Cahiers $d u$ MONDE RUSSE

\section{Cahiers du monde russe}

Russie - Empire russe - Union soviétique et États indépendants

$43 / 4 \mid 2002$

Intellectuels et intelligentsia

\title{
Arno J. Mayer, Les Furies
}

\section{Tamara Kondratieva}

URL : https://journals.openedition.org/monderusse/4063

DOI : $10.4000 /$ monderusse. 4063

ISSN : $1777-5388$

\section{Éditeur}

Éditions de l'EHESS

\section{Édition imprimée}

Date de publication : 30 décembre 2002

Pagination : 813-815

ISBN : 2-7132-1796-2

ISSN : $1252-6576$

\section{Référence électronique}

Tamara Kondratieva, «Arno J. Mayer, Les Furies », Cahiers du monde russe [En ligne], 43/4 | 2002, mis en ligne le 18 juin 2009, consulté le 03 septembre 2022. URL : http://journals.openedition.org/ monderusse/4063 ; DOI : https://doi.org/10.4000/monderusse.4063

Ce document a été généré automatiquement le 3 septembre 2022

Tous droits réservés 


\title{
Arno J. Mayer, Les Furies
}

\author{
Tamara Kondratieva
}

\section{RÉFÉRENCE}

Arno J. MAYER, Les Furies. Violence, vengeance, terreur aux temps de la Révolution française et de la révolution russe. Paris, Fayard, 2002, 680 p.

1 Arno J. Mayer, professeur à l'université de Princeton, est connu en France par la grande envergure de son œuvre. Ont ainsi été traduits en français La persistance de l'Ancien Régime: l'Europe de 1848 et la Grande Guerre (Flammarion, 1983) et La Solution finale dans l'histoire (La Découverte, 1990). Les Furies sont également un ouvrage de réflexion large et pertinent, conçu par Arno Mayer pendant son séjour en France à la fin des années 1980, dans un contexte fortement marqué par le bicentenaire de la Révolution française et la perestroïka en URSS et à l'est de l'Europe. Un contexte particulièrement propice aux comparaisons, dont le caractère simpliste - surtout en ce qui concerne la Terreur dans la France et la Russie révolutionnaires - exaspérait Mayer. Encouragé par Maurice Agulhon, l'historien américain a donné une série de conférences au Collège de France avec l'intention d'apporter un éclairage nouveau sur « les aspects les plus atroces et les plus controversés du phénomène révolutionnaire ». À partir de là, il a fait paraitre un livre où est tentée « une lecture empathique des Furies » qui exercent leur colère aux temps des révolutions française et russe.

2 Tentative réussie. Tout d'abord grâce à une démarche préalable qui consiste à mettre au clair les concepts de travail - révolution, contre-révolution, violence, terreur, vengeance, religion - qu'un usage amplifié et accommodant a rendus confus. La première partie de l'ouvrage ("Jalons conceptuels») apporte les précisions théoriques aux contenus que l'auteur se propose d'exploiter en appliquant ces concepts à l'analyse comparative des Furies vengeresses. Il montre qu'on ne peut rendre aucun d'eux opératoire sans y intégrer les autres. Afin de mener à bien l'analyse des Furies, il convient ainsi - et c'est là l'originalité de l'approche comparatiste du livre - de fonctionner en utilisant simultanément ces six concepts inséparables. 
3 Les autres parties de l'ouvrage réussissent une mise en perspective comparative du processus de déchaînement des Furies à la suite du rapport dialectique entremêlant les terreurs révolutionnaire et contre-révolutionnaire ("Crescendo de violence»), les fureurs paysannes («Condescendance métropolitaine et méfiance rurale»), les passions religieuses ( La contestation du sacré ») et les conflits avec l'ennemi extérieur («Un monde sorti de ses gonds »). Dans le choix des faits historiques et des arguments de comparaison, l'auteur respecte scrupuleusement les contextes propres à chacune des révolutions, de façon à montrer comment montent la violence, la vengeance et la terreur.

4 «De fait - écrit Mayer dans l'introduction-interpréter la Révolution française et la révolution russe, et plus particulièrement leurs Furies, en négligeant cette dialectique, c'est risquer d'en faire des chapitres infâmes de l'histoire de la folie et du crime humains ou des calamités aussi terribles que fatales - d'inévitables tragédies du réel. En général, les maitres d'œuvre de ce type de constructions attribuent le crescendo de violence à la convergence entre la force irrésistible d'un système de croyance messianique et manichéen et la volonté de fer d'un dirigeant tout-puissant et démoniaque. En dernière analyse, ces explications qui font la part trop belle à l'idéologie et à la personnalité présentent le gros défaut d'être littéralement obsédées par une cause unique». Contrairement à ceux qui continuent à plaider et à juger, l'auteur de ces lignes rejoint tout historien critique qui «se contente de demander 'pourquoi ?' et accepte que la réponse ne soit pas simple».

Le lecteur qui porte un intérêt particulier à la révolution russe et à ses prolongements dans l'Union soviétique trouvera dans ce livre une argumentation systématisée et solide contre les simplifications toujours en cours. Dues aux polémiques du temps de l'URSS, celles-ci sont à la recherche de la cause unique ou d'un seul responsable d'une histoire longue de soixante-dix ans et de ses manifestations les plus violentes comme la guerre civile, la collectivisation et la terreur des années 30. À l'instar de Claude Lefort ( $L a$ Complication: retour sur le communisme, Fayard, 1999) et fidèle à ses propres travaux, Mayer s'érige contre les schémas idéologisants au profit d'une approche historisante et se donne pour tâche de faire une synthèse critique qui éviterait "d'exagérer le rôle de l'idéologie et la place du grand leader, voire des deux ensemble ». Persuasif dans sa conviction "qu'il n'est pas d'explication historique sans comparaison, explicite ou implicite », il réussit à montrer que la terreur est irréductible aux seuls préceptes idéologiques, mais qu'elle se développe aussi pour des motifs irrationnels alimentés par la dialectique de la révolution et de la contre-révolution, que les violences obéissent à la logique implacable de la guerre civile et à l'engrenage de vengeances provoqué dans le milieu rural par le choc entre modernisateurs athées d'un côté et paysans croyants de l'autre.

6 Toutefois, si le lecteur juge que les démonstrations érudites de Mayer sont de qualité inégale et perdent par moments de leur force sous le poids d'un excès de données factuelles, de détails minutieux, ou à cause de leur interprétation, il ne doit pas pour autant mettre en doute la valeur globale de l'ouvrage, quitte à refuserd'objectiver là où l'historiographie tarde à réviser ce qu'elle avait produit avec pertes et fracas partisans. 